TURIZAM

Volume 15 , Issue 2

53-64 (2011)

\title{
Decision Factors for Domestic Package Tours - Case Study of a Region in South Africa
}

\author{
Nerine Bresler* \\ Received: November 2010 | Accepted: January 2011
}

\begin{abstract}
This article argues that perceived risk is an inhibitor for the emerging domestic market to develop a culture of going on holiday, which is necessary for the sustainable development of tourism in South Africa. Entrenching a culture of travel can be expedited through appropriate package tours in the same way as it stimulated domestic travel in former Eastern European societies. Packaged tours provide convenience, and both psychological and financial security in a single transaction which can be considered a surrogate for the benefit of risk avoidance when visiting friends and relatives. A survey was conducted in the most promising region, namely the province Gauteng, amongst the potential market to identify the importance of decision factors for domestic packaged tours. The most important perceived decision criteria were cancellation possibility, affordability, and safety whilst on tour and the three least important were radio promotion, train transport and proximity. The results may be used by the National Department of Tourism to promote domestic tourism, as well as by new and small tour operators to improve decision-making and render competition more knowledge-based. It would thus serve the needs of both tourist buyers and tourism sellers and contribute to sustainable development.
\end{abstract}

Keywords: Inclusive tours, domestic tourism, decision criteria, product bundling, group package tour attributes, Gauteng province.

\section{Introduction}

It is a strategic objective of the Department of Tourism (NDT) to encourage domestic tourism in order to entrench a culture of travel amongst South Africans for sustainable tourism growth (NDT, 2OIOa: 6; NDT, 2OIOb: 4O). For sustainability a vibrant domestic market is required as it supports innovation and international tourism marketing (Rule, Viljoen,

* Department of Tourism Management, School of Tourism and Hospitality, Faculty of Management, Bunting Road Campus, University of Johannesburg, PO Box 524, Auckland Park, 2006, South Africa; nbresler@uj.ac.za; tel.oo 2711559 1036, fax. 0027115591011 
Zama, Struwig, Langa \& Bouare, 2004: 80). Not many South Africans travel for holiday purposes or consume traditional tourism products and services such as paid for accommodation, tour busses and rental cars, or visit tourist attractions. A similar scenario was found in the United Kingdom (UK) in 1985 when holiday-taking was not universal among the adult population (Hughes, I99I: I94), as well as in the former Eastern European societies; for example the Soviet Union, Poland, Czechoslovakia, Bulgaria and the German Democratic Republic (Kreck, 2OIO: 305). Large scale domestic tourism was promoted in these societies for leisure and recreation purposes. It was believed that domestic tourism would lead to an overall development of personality, which would in turn help the economy and finally improve the standard of living (Kreck, 2OIO: 3OI). Tourism development normally follows an industrialization and urbanisation process which brings about economic and social changes, and affords people more leisure time and disposable income (Urry, 20O2: I8). South Africa (SA) experienced a similar process of economic and social change since the political transformation in the early I990s.

The author believes that development in the domestic sector may be expedited through group package tours (GPTs) which remove some of the inhibitors to travel, in that GPTs provide convenience, and both psychological and financial security in a single purchase transaction to individuals (Middleton, Fyall, Morgan \& Ranchhod, 2009: 43I). This may be the reason for visiting friends and relatives (VFR) (Moscardo, Pearce, Morrison, Green \& O’Leary, 2OIO: I46; Urry, 2002: 7).

There are different types of GPTs depending on the degree of pre-arranged services (George, 2008: 264; Mak, 2004: 35; Money \& Crotts, 2003: I95; Wang, Hsieh \& Huan, 2000: I77; Wong \& Kwong, 2004: 58I). This study is based on the definition by Middleton et al. (2009: 429) whereby a tour package is defined as "a quality assured, repeatable offer comprising two or more elements of transport, accommodation, food, destination attractions, other facilities and related services such as travel insurance. They are marketed to the general public, described in print or electronic media, and offered for sale to prospective customers at a published, inclusive price, in which the costs of the product components cannot be separately identified". The study excludes custom-made packages which are growing in popularity concurrently with the sophistication of tourists and the availability of on-line travel options (Enoch, I996: 6OI), as well as group tours organised by the public sector and trade unions for ideological reasons (Koch \& Massyn, 2OOI: I7I; NDT, 2OIOb, section B: 28; Kreck, 2OIO: 3OI-3O5), as these are irrelevant here.

The NDT (2OIOb: 39) requires of domestic tourism to address inter alia volume growth, geographical spread, diversity of products, affordability in travel, reduce seasonality, provide access to travel information and create a culture of going on holiday; especially among the black population and the youth. GPTs may make a contribution in achieving all these national objectives, but more specifically creating a culture of holidaying among the black youth, who do not know how to go on holiday (NDT, 2OIOb, Section B: 28). The development of affordable packages had been identified to promote regular travel as a lifestyle activity for the domestic market which is predominantly young and black. More than half $(52 \%)$ of them are between I8 and 34 years in 2009, and 74\% Black. This disproportionate representation is also true for the VFR market (Rule et al., 2004: 84). Travel in the domestic market is seasonal, with peaks during school holidays coinciding high-seasons for international visitors (SA Tourism, 2OIO: 85, 68).

The assembly of GPTs for any market requires research to develop relevant packages that will meet potential visitors' needs (Bergery \& Eckersley, 2007: 2; Kreck, 2OIO: 3O3; Mid- 
dleton et al., 2009: 432), yet no research could be found on decision criteria for the selection of domestic tours for an untapped market. There is a research gap in domestic tourism, especially from a consumer perspective in situation-specific contexts (Opperman \& Chon, I997: 8I; Pike, 2OO3: 328-9; Rewtrakunphaiboon \& Opperwal, 2OO4: I82). According to Hudson and Ritchie (2002) domestic tourism are of the most neglected and under-researched categories in tourism analysis.

The purpose of this study is to identify the importance of factors people take into consideration when going on a GPT for leisure purposes in SA. Even though this study focuses on the development of packages from a potential tourist perspective, and not the planning of tourism, the results may be used by the Department of Tourism to promote domestic tourism, as well as by new and small tour operators to improve decision-making and render competition more knowledge-based. It would thus serve the needs of both tourist buyers and tourism sellers and contribute to sustainable development. The limitation of the study is that the perspective is limited. It excludes respondents from other provinces, a factor analysis to simplify interpretation and follow-up qualitative study, as well as a participant perception of existing tours.

\section{Literature Review}

An overview of pertinent literature will be given to elucidate the problem, its context and the contribution of this study. The problem arises from challenges SA faces in growing domestic tourism, whilst the contribution lies within the role GPTs play in delivering the benefits tourists seek to stimulate demand, and the literature will be presented as such.

\section{Domestic Tourism in South Africa}

The information in this section is based on the Global Competitiveness Study (SA Tourism, 2004), the Tourism Growth Strategy (SA Tourism, 2007), the Marketing Growth Strategy (SA Tourism, 2OO8) and the Draft National Tourism Sector Strategy (NDT, 2OIOb) unless otherwise indicated. These are consecutive documents based on similar information addressing similar issues.

The domestic market is becoming increasingly important as it accounts for $75 \%$ of volume (trips not value). However, it contributes only 22\% (R22 billion) of total tourism revenue in 2009, and decreased by I3\% from 2008 (SA Tourism, 20IO: 66, 75). The holiday market is not only a small segment, but the consumption of tourism products and services whilst on holiday are also limited, and the growth is slack. Only I2\% (3.6 million) of domestic trips was for holiday purposes, and it declined by 30\% from 2008. The average trip-cost was R290; a decline of $22 \%$ from 2008 (SA Tourism, 2OIO: 77). Due to the prevalence of VFR $87 \%$ of nights were spent in unpaid accommodation; up from $82 \%$ in 2008. Mini bus taxis and private vehicles are the most popular forms of transportation. The use of aeroplanes (I\%), trains (I\%) and commercial tour busses (2\%) are minimal and also decrease (SA Tourism, 2OIO: 74, 8I). VFR tourists spend significantly less than other types of domestic tourists. In 2OOI it was less than a quarter of the amount spent by holiday and leisure tourists and thus requires development initiatives (Rule et al., 2004: 97). 
The consumer segment of the domestic market is categorised as established, emerging and untapped, and this study focuses on the emerging market because it has the greatest potential for growth. A development constraint in the domestic market is that it has a fairly high level of interest in different holiday activities, but shows low levels of product usage in 2009, other than socialising (84\%) and shopping (28\%). Only 9\% visited beaches, $7 \%$ took part in nightlife, $5 \%$ visited cultural, historical and heritage sites, $5 \%$ went to a casino, $4 \%$ to natural attractions, and 4\% viewed wildlife (SA Tourism, 2OIO: 72). Tourists' usage of holiday products does not appear to live up to their level of interest. The absence of products which fall into the high-desire, high-usage profile raises questions about familiarity with the products, access constraints, affordability as well as their understanding of the utopian desire for a holiday (SA Tourism, 2004: 345).

\section{Group Packaged Tours}

To appreciate the complexity of assembling packages it is necessary to understand the role of tour operators and the benefits of GPTs for pleasure trips (Čavlek, 2006; Sheldon, I994: 4OO). In every case the package is assembled from the five basic elements of the overall tourism product (destination attractions and environment, destination facilities and services, accessibility of the destination, images of the destination and price to the consumer) plus any value from their own tour operations, such as branding, convenience, price guarantees and contractual agreements (Mak, 2004: 35; Middleton et al., 2009: I23, 430). Tour operators purchase the components from product owners, promote and sell GPTs directly or through travel agents, to consumers who pay for it in advance in a single transaction. They thus enable different product owners to sell their offerings (stock) in advance, and reduce their risk and cost, yet provide quality assurance of these components not under their direct control, in a branded context, and guarantee delivery of the promise with legal liability (Čavlek, 2006: I56; George, 2008: 260-265; Middleton et al, 2009: 43I; Sheldon, I994: 4OO; Wang, Hsieh, Chou \& Lin, 2007: 363). In addition to bulk buying, tour operators drive down unit cost further by spreading tours throughout the year which may increase holiday participation, because there is a direct relationship between cost, price and demand (Čavlek, 2006: I63; Holloway, 2002: 49). Ultimately tour operators overcome the natural inefficiency that is inherent in matching demand and supply (Čavlek, 2006: I57; Middleton et al., 2009: 430), and influence the sustainability of a destination in that they choose the individual suppliers and influence the consumer's choice (Čavlek, 2005: I75; Telfer \& Sharpley, 2008: I69; Van Wijk \& Persoon, 2006: 382).

Tour operators compete primarily on price and product portfolios, but as markets mature the focus switches to branding, imaging and niche packages (Davies \& Downward, 2007: I245; Enoch, I996: 604, Middleton et al, 2009: 43I). The price a tourist is willing to pay depends on the utility he/she expects to derive from the benefits of the individual components, and the market is notorious for its price sensitivity (Mak, 2004: 38; Middleton et al, 2009: 43I). A GPT can be put together to meet just about any consumer demand as long as potential profit induces a tour operator to create it (Mak, 2004: 35). It is generally more popular for first-time and international travel than for domestic trips (Enoch, 1996: 600; Mak, 2004: 34, 4O; Wong \& Kwong, 2004: 582).

Mak (2004: 36-39) argues that the principal perceived benefits for tourists are its certainty and predictability plus: convenience, cheaper price, familiarity with a destination, 
ability to see and do more, experts take care of important detail allowing the traveller to relax and obtain maximum enjoyment, no surprises, hotels are of a guaranteed quality, restaurants are safe and representative of what is unique to the local culture, the itinerary ensures that the must see spots are visited. Middleton et al. (2009: 432) adds the following benefits: not experiencing a personal sense of failure if things go wrong, reassurance of product quality at the point of sale, the right of redress, reduced intangibility, increased overall appeal, and matching demand with supply. Preferences differ by traveller for example; some may place a high value on companionship and others on tour tempo, scenery, shopping locations, sport facilities, novelty, departure dates, or tourist involvement (Bowen, 200I: 59; Chen, Hwang \& Lee, 2006: II68; Enoch, I996; Wong \& Kwong, 2004: 582).

The product component preferences are endless for different socio-cultural contexts (Enoch, I996: 603; Kozak, 2OOI: 399). People who travel together share similar tour preferences reflected in their personal traits (Enoch, 1996: 604; Mak, 2004: 39). For example the Chinese are group-orientated, and value prestige, courtesy, prudence, trustworthiness and contentedness and are inclined to prefer inclusive GPTs patronizing 5-star international hotels, endorsed by reputable tour leaders (Mak, 2OO4: 39; Wang, Hsieh \& Chen, 20O2: 495; Wong \& Kwong, 20O4: 583). However, internationally the trend is towards more flexible and less all-inclusive escorted tours and the emphasis is more on doing than seeing (Mak, 2004: 4O).

It must be born in mind that there are many reasons why tourists do not prefer a GPT but to travel independently; one of the main reasons being that first time buyers with sufficient income had already entered the market and became experienced travellers (Mak, 2004: 36-4O, Middleton, I99I: I87). The relevance to this study is that GPTs can be a booster to domestic tourism growth by mitigating the risk in decision-making for first time buyers with limited income, but the product life cycle (PLC) of GPTs will reach maturity once this market become experienced, more knowledgeable and certain of what they want and find acceptable. Domestic tourism development and the PLC of GPTs in SA will then follow the same pattern as in the developed world (Čavlek, 2005: I83; Cole \& Razak, 2009: 342; Harrison, 2OOI: 24). Operators will then have to look for the core advantages of packages (pricing, convenience, reliability and easy access) to deliver significant price and product advantages. Success will lie in more sophisticated marketing, better segmentation to meet identified customer needs, providing most of the real benefits of independent travel, but product quality assured, within an inclusive good value price (Čavlek, 2006: I7I; Middleton, I99I: I89I92 Ryan, I99I: 76).

From the preceding discussion it is evident that the tour operator needs to take multiple variables into consideration in decision-making, but rely on an intuitive understanding of the market (Bergery \& Eckersley, 2007: 2; Wang et al., 2007: 362). SA does not have adequate, relevant, tailor-made GPTs based on a true understanding of the needs and desires of the emerging domestic market, and packages are generally a high-cost option. This calls for consideration of price elasticity and careful marketing.

\section{Research Methodology}

The purpose of this study was to identify GPT attributes of importance to the SA tourist in order to develop domestic packages that will satisfy their perceived needs. It is an exploratory, quantitative study. A survey was conducted amongst 288 respondents to rate the perceived importance of 46 factors/attributes people take into consideration, when deciding to 
go on a tour in SA, on a 5-point Likert-scale anchored by do not at all agree (I) and totally agree (5). The questionnaire was developed from a literature search and for purposes of validity the factors (GPT attributes) were contextualised to be relevant for the emerging domestic tourism market in SA (Pike, 2003: 329). The list of factors contains functions performed by tour operators, benefits tourists seek and product components (Čavlek, 2006: I57; Mak, 2004, 36-39; Middleton et al., 2009: I23, 430). The questionnaire also contains some demographic information and was finalised in consultation with a member of the SA Market Research Association and the university's statistical services; Statkon. The latter was also responsible for data capturing and analysis using SPSS for Windows. The instrument was piloted amongst 64 potential tourists and no changes were made because the scale items of the pilot had good internal consistency, with a Cronbach alpha coefficient of $0.849 ;>0.7$ is the recommended a minimum (Pallant, 2005: 90). The scale items, or variables, are the GPT attributes.

Gauteng province was selected for conducting this study, as it is the major source market with the highest spenders per trip (RIO4O), accounting for 4I.3\% of domestic tourism spent, in comparison to the average of R73O per trip (SA Tourism, 2OIO: 78-79). The survey was administered in different areas in Gauteng, mostly outside travel agencies with high pedestrian flow, during April 2OIO. The sample is purposeful as care was taken to interview persons reflective of the emerging tourism market. A descriptive profile is shown in table I. The majority of the respondents were younger than 35 years of age (65.7\%) and Black (61.5\%). More females (54.5\%) than males (45.5\%) were interviewed and within population groups the distribution female/male was fairly balanced. Within age groups there were proportionally more Asians and Whites that is older.

As with any method and sample, there are limitations to this study. Firstly, the sample is

Table 1 Sample of prospective tourists selecting a domestic packaged tour

\begin{tabular}{|c|c|c|c|c|c|c|c|c|}
\hline \multirow{3}{*}{$\begin{array}{l}\text { Age group / } \\
\text { Age } \\
18-24\end{array}$} & \multicolumn{6}{|c|}{ Population groups; count and \% within age group } & \multirow{3}{*}{$\begin{array}{r}\begin{array}{r}\text { Total } \\
\text { count }\end{array} \\
107\end{array}$} & \multirow{3}{*}{$\begin{array}{l}\text { \% } \\
37.2\end{array}$} \\
\hline & \multicolumn{2}{|c|}{ Asian and White } & \multicolumn{2}{|c|}{ Black } & \multicolumn{2}{|c|}{ Coloured } & & \\
\hline & 17 & $15.9 \%$ & 71 & $66.4 \%$ & 19 & $17.8 \%$ & & \\
\hline $25-35$ & 12 & 14.6 & 53 & 64.6 & 17 & 20.7 & 82 & 28.5 \\
\hline $36-45$ & 20 & 29.4 & 36 & 52.9 & 12 & 17.6 & 68 & 23.6 \\
\hline 46 and older & 11 & 35.5 & 17 & 54.8 & 3 & 9.7 & 31 & 10.8 \\
\hline Total count & 60 & & 177 & & 51 & & 288 & \\
\hline$\%$ within age & \multicolumn{2}{|c|}{$20.8 \%$} & \multicolumn{2}{|c|}{$61.5 \%$} & \multicolumn{2}{|c|}{$17.7 \%$} & & $100 \%$ \\
\hline Female & \multicolumn{2}{|c|}{$20.9 \%$} & \multicolumn{2}{|c|}{$60.8 \%$} & \multicolumn{2}{|c|}{$18.4 \%$} & 158 & $54 \cdot 5$ \\
\hline Male & \multicolumn{2}{|c|}{$22.0 \%$} & \multicolumn{2}{|c|}{$61.4 \%$} & \multicolumn{2}{|c|}{$16.7 \%$} & 132 & 45.5 \\
\hline
\end{tabular}

not representative of respondents from other provinces. Secondly, a factor analysis may elicit salient factors that would simplify the interpretation. Thirdly a follow-up qualitative study, based on GPT participation would enrich the study. Lastly, the perspective is limited in that it excludes a participant evaluation of existing tours. 


\section{Findings}

\section{Importance of Factors When Selecting a Domestic Tour}

Respondents had to indicate their agreement with a list of 46 factors/decision criteria people tend to take into consideration when selecting a domestic tour, on a 5-point scale, anchored by do not at all agree (I) and totally agree (5). The results are reflected in table 2.

Table 2 Mean rating of the decision criteria when selecting a domestic tour $(N=288)$

\begin{tabular}{|c|c|c|c|}
\hline Item no. & $\begin{array}{l}\text { Statements about organised tours I would select on a scale } \\
\text { of } 1-5 \text { where } 5 \text { is totally agree }\end{array}$ & Mean & $\begin{array}{l}\text { Std. } \\
\text { deviation }\end{array}$ \\
\hline 4 & I must be able to cancel should anything happen that I have no control over & 4.53 & 0.909 \\
\hline 1 & I select tours that are affordable & 4.50 & 0.918 \\
\hline 32 & Safety and security while on tour is very important for me & $4 \cdot 44$ & 0.952 \\
\hline 33 & I select tours that will take me away from the stresses and strains of work & 4.43 & 0.931 \\
\hline 24 & It is very important to me that the quality of the tour organiser's service is good & $4 \cdot 40$ & 0.902 \\
\hline 2 & I prefer tours that provide value for money & $4 \cdot 40$ & 1.023 \\
\hline 3 & It's important that the price include insurance in case of an accident & $4 \cdot 39$ & 0.999 \\
\hline 27 & I select tours where the experience will live up to expectations created & $4 \cdot 37$ & 0.912 \\
\hline 40 & I prefer tours where I'll have experiences that I can share afterwards & 4.30 & 1.015 \\
\hline 39 & I prefer tours with a well-informed tour-guide so as to enhance learning & 4.24 & 1.010 \\
\hline 25 & I prefer all the components of the tour to be of equal quality & 4.23 & 0.969 \\
\hline 41 & I normally select tours offering excitement & 4.23 & 1.036 \\
\hline 42 & I prefer tours that include a variety of entertainment & 4.22 & 1.072 \\
\hline 31 & Tour operators must be able to deal with unforeseen problems efficiently & 4.21 & 1.072 \\
\hline 26 & I select tours organised by operators whom I believe to be competent & 4.16 & 1.063 \\
\hline 29 & I normally book on tours that allow for leisure time to do my own things & 4.15 & 1.065 \\
\hline 5 & $\begin{array}{l}\text { The tour must preferably include accommodation, transport and three meals a day, } \\
\text { not only accommodation and transport }\end{array}$ & 4.11 & 1.156 \\
\hline 34 & I prefer tours where I do not have to share a room with someone I do not know & 4.10 & 1.281 \\
\hline 15 & It is important for me to go on tours organised by a well known branded operator & 3.99 & 1.188 \\
\hline 12 & I prefer to stay in well known places that are graded & 3.95 & 1.162 \\
\hline 28 & Convenience is important; all arrangements must be made for me & 3.91 & 1.184 \\
\hline 43 & I normally select tours that include scenic attractions in nature & 3.88 & 1.174 \\
\hline 23 & I usually go on tours that my friends or family have recommended & 3.87 & 1.167 \\
\hline 11 & I prefer tours where one can stay at a resort for several nights & 3.85 & 1.194 \\
\hline 45 & I prefer touring to well- known destinations & 3.84 & 1.206 \\
\hline 14 & Ideally a tour should be for about a week & 3.75 & 1.240 \\
\hline 36 & I prefer to go on tours where it is possible to make new friends & 3.73 & 1.238 \\
\hline 38 & I prefer touring with people in my own age group & 3.70 & 1.279 \\
\hline 7 & For distant destinations, I prefer a combination of a bus and aeroplane & 3.70 & 1.327 \\
\hline 44 & I select tours offering opportunities for physical activity & 3.69 & 1.316 \\
\hline 22 & I prefer to go to a travel agent to make my bookings for a tour & 3.66 & 1.306 \\
\hline
\end{tabular}




\begin{tabular}{|c|c|c|c|}
\hline Item no. & $\begin{array}{l}\text { Statements about organised tours I would select on a scale } \\
\text { of 1-5 where } 5 \text { is totally agree }\end{array}$ & Mean & $\begin{array}{l}\text { Std. } \\
\text { deviation }\end{array}$ \\
\hline 30 & I prefer to go on tour during quiet times, when it is not school holidays & 3.59 & 1.421 \\
\hline 8 & I prefer touring by luxury coach & 3.57 & 1.278 \\
\hline 10 & I prefer to overnight at a hotel, not a guest house or B\&B & 3.56 & 1.382 \\
\hline 17 & I prefer to find information about tours on the internet & 3.56 & 1.312 \\
\hline 13 & I prefer tours of 3-4 days duration & 3.44 & 1.352 \\
\hline 35 & I prefer tour groups that are small & 3.41 & 1.387 \\
\hline 19 & I prefer to find information about tours in brochures/ pamphlets & 3.31 & 1.251 \\
\hline 37 & I prefer special interest tours for example watching flowers or wildlife & 3.28 & 1.345 \\
\hline 18 & I normally make my booking for tours on the internet through websites & 3.07 & 1.334 \\
\hline 16 & I normally go on tours that are advertised in magazines & 2.69 & 1.294 \\
\hline 20 & I usually look in newspapers for information on tours & 2.68 & 1.237 \\
\hline 6 & I like to have breakfast only; not three meals a day & 2.66 & 1.510 \\
\hline 46 & I prefer touring to destinations nearby & 2.63 & 1.451 \\
\hline 9 & I prefer to travel by train when on a tour & 2.42 & 1.398 \\
\hline 21 & It is mostly the radio which influences me to join a particular tour & 2.31 & 1.273 \\
\hline
\end{tabular}

The seven most important criteria for selecting a tour are benefit and risk avoidance related namely the possibility to cancel with a mean score of 4.53 , affordability 4.50 , safety 4.44 , stress relieve 4.43 , quality services by the organiser $4.4 \mathrm{O}$, value for money $4.4 \mathrm{O}$, and accident insurance cover 4.39. Promotion (by radio, newspaper or magazines) was not important, as well as to visit a destination nearby, and to travel by train, all with a mean score below 3.00. The range of the mean scores is a fairly small 2.22 (difference between the smallest 2.3I and largest 4.53 values) and the distribution is slightly positively skewed, as most items were considered fairly important to important (Malhotra, 2007: 46I-2; Tustin, Ligthelm, Martins \& Van Wyk, 2005: 55O-554). The variance, or deviation from the mean expressed in the same units as the data, was not much and it ranges between $0.9 \mathrm{O} 2$ for quality services by the organiser, to I.42I for tours not during school holidays. This indicates that most respondents agree on items with low standard deviations and agree less on those with higher standard deviations. It would seem that respondents agree on decision factors they rate as important and disagree more on what is not important. The results reveal that GPTs could be offered during quiet times when it is not school holidays, to reduce seasonality.

The question arose if the findings would be similar for different age, population, and gender groups. The data had to be tested for normality of the distribution of scores (Pallant, 2005: 53-62). Normal is used to describe a symmetrical, bell-shaped curve, which has the greatest frequency of scores in the middle, with smaller frequencies towards the extremes. Descriptive statistics for normality of the age, population, and gender groups were thus calculated. These were: the mean, 95\% confidence interval of the lower and upper bound for the mean, $5 \%$ trimmed mean (removing the top and bottom $5 \%$ of cases and recalculate the mean in order to determine if extreme scores influence the mean), the median, variance, standard deviation, minimum, maximum, range, interquartile range, skewness, and kurtosis, standard error, as well as the Kolmogorov-Smirnov and Shapiro-Wilk tests which calculates the level of significance for differences from a normal distribution (Pallant, 2005: 57). The analysis indicated normality which is common in larger samples. Further statistical tests 
for homogeneity of variances in the means indicate that the differences between the two gender groups, the three population groups, and the four age groups, were so small that they did not reach significance.

\section{Discussion}

The seven most important of the 46 selection criteria reflects some of the core functions of GPTs and are benefit and risk avoidance related, namely the possibility to cancel, affordability, safety, stress relieve, quality services by the organiser, value for money, and accident insurance cover. Information and promotion (by radio, newspaper or magazines) was not important, as well as to visit a destination nearby. The barriers to go on GPTs and participate in holiday travel seems to be risk related; mainly in terms of cost (cancellation and affordability) and living up to expectations (competent operator and enjoyable holiday).

The advice for new and small tourism operators is to select only reputable, affordable tour components, make only promises that can be delivered and ascertain what the emerging market considers to be scenic, exciting, and entertaining. With respect to enabling factors for holiday participation, it would seem that access by means of distribution is more important than by means of information. In marketing terms, the role of intermediaries is more important than promotion to stimulate demand.

\section{Contribution}

From a theoretical perspective the research makes a specific contribution in that it identified risk (financial and emotional) as a barrier for the emerging market to go on holiday. GPTs reducing these risks can thus be used by developing countries to stimulate and promote participation in domestic tourism, similar to the use of group tours to stimulate domestic travel in former Eastern European societies. Secondly the findings provide a contribution to the vacuum of research data for improved decision making by tour operators to render competition more knowledge-based. Thirdly it broadens the theoretical domains used in understanding travel decision-making, as well as domestic tourism which are of the most neglected and under-researched categories in tourism analysis. Lastly the findings can be used to elucidate consumer behaviour in response to bundling (GPTs), and the impact of package holidays on consideration and intention to visit.

From a practical perspective the findings may provide useful information for new and small tour operators in assembling and marketing GPTs in a sustainable manner. To survive in a very competitive market, enterprises must strategically link up with others delivering different parts of the integral tourism product (GPTs). It may also be used by NDT in support of their strategy to create a culture of holidaying for the emerging market.

It is suggested that follow-up research is undertaken to address the shortcomings of the study. The study area may be extended to include respondents from the other eight provinces of South Africa. A factor analysis can be done to elicit salient factors which would simplify the interpretation for practical application purposes, and the data may be triangulated with a follow-up qualitative phase. In addition, satisfaction with existing GPTs will provide more insight into existing domestic tour packages that would enrich the findings. 


\section{References}

Bergery, L. \& Eckersley, D.A. (2007). Changing tourist behaviour and the need for new products, E-Review of Tourism Research (eRTR), 5 (I) http://ertr.tamu.edu

Bowen, D. (2OOI). Antecedents of consumer satisfaction and dissatisfaction (CS/D) on longhaul inclusive tours - a reality check on theoretical considerations. Tourism Management 22, 49-6I.

Čavlek, N. (2005). The impact of tour operators on tourism development; a sequence of events. In Aramberri, J. \& Butler, R. (eds), Aspects of tourism; tourism development issues for a vulnerable industry, pI74-I92. Channel View Publications, Clevedon.

Čavlek, N. (2006). Travel and tourism intermediaries. In Dwyer, L. \& Forsyth, P. (eds), International handbook in the economics of tourism, I55-I72. Edward Elger Publishing Ltd., Cheltenham.

Chen, H-J., Hwang, S-N. \& Lee, C (2006). Visitor's characteristics of guided interpretation tours. Journal of Business Research, 59, II67-II8I.

Cole, S. \& Razak, V. (2009). Tourism as future. Futures 4I, 335-345.

Davies, B. \& Downward, P. (2007). Exploring price and non-price decision making in the UK package tour industry: insights from small-scale travel agents and tour operators. Tourism Management 28, I236-I26I.

Department of Tourism. (2OIOa). Medium term strategic plan; 2OIO/2OII-2OI4/2OI5. Pretoria, NDT.

Department of Tourism. (2OIOb). Draft National Tourism Sector Strategy (NTSS) to accelerate the responsible growth of the tourism industry from 2OIO-2OI5, May. NDT, Pretoria.

Enoch, Y. (I996). Contents of tour packages: a cross-cultural comparison. Annals of Tourism Research 23(3), 599-6I6.

George, R. (2008). Marketing tourism in South Africa, 3rd ed. Oxford SA, Cape Town.

Harrison, D. (ed). (2OOI). Tourism and the less developed world: issues and case studies. CABI Publishing, Oxon.

Holloway, J.C. (2OO2).The business of tourism, 6th ed. Essex, Pearson Education Ltd.

Hudson, S \& Ritchie, B. (2OO2). Understanding the domestic market using cluster analysis: a case study of the marketing efforts of Travel Alberta. Journal of Vacation Marketing, July, 8: 263-276.

Hughes, H.L. (I99I). Holidays and the economically disadvantaged. Tourism Management, September: I85-I92.

Koch, E \& Massyn, P. (2OOI). South Africa's domestic tourist sector: promises and problems. In Ghimire, K. (ed), The native tourist: mass tourism within developing countries, p.I42I7I. Earthscan, London.

Kozak, M. (2OOI). Comparative assessment of tourist satisfaction with destinations across two nationalities. Tourism Management, 22, 39I-4OI.

Kreck, L.A. (2OIO). Tourism in former Eastern European societies: ideology in conflict with requisites. In Page, S. \& Connel, J. (eds), Tourism, vol. I, The evolution of the subject of study, p.296-308. Sage Publications Ltd., London.

Mak, J. (2004). Tourism and the economy. University of Hawaii Press, Honolulu.

Malhotra, N.K. (2007). Marketing research; an applied orientation, 5th ed. Pearson Prentice Hall: New Jersey. 
Middleton, V.T.C. (199I). Whither the package tour. Tourism Management, September: I85I92.

Middleton, V.C.T., Fyall, A., Morgan, M. \& Ranchhod, A. (2009). Marketing in travel and tourism, 4th ed. Elsevier. Butterworth-Heinemann, Oxford.

Money, R.B. \& Crotts, J.C. (2003). The effect of uncertainty avoidance on information search, planning, and purchases of international travel vacations. Tourism Management 24, I9I-2O2.

Moscardo, G., Pearce, P., Morrison, A., Green, D. \& O’Leary. (2OIO). Developing a typology for understanding visiting friends and relatives markets. Journal of Travel Research, 38(3), 25I-259.

NDT see Department of Tourism.

Opperman, M. \& Chon, K-S. (I997). Tourism in developing countries. International Thomson Business Press, London.

Pallant, J. (2005). SPSS survival manual, a step by step guide to data analysis using SPSS version I2, 2nd ed. Open University Press, Berkshire.

Pike, S.D. (2003). The use of Repertory Grid Analysis to elicit salient short break holiday destination attributes in New Zeeland. Journal of Travel Research, 4I(3), 326-33O.

Rewtrakunphaiboon, W. \& Opperwal, H. (2004). Effects of holiday packaging on tourist decision making: some preliminary results. In Crouch, G.I., Purdue, R.R., Timmermans, H.J.P. \& Uysal, M. (eds), Consumer psychology of tourism, hospitality and leisure, volume 3, p.I8I-I88. CABI Publishing, Oxfordshire.

Rule, S., Viljoen, J., Zama, S., Struwig. J., Langa, Z. \& Bouare, O. (2004). Visiting friends and relatives: South Africa's most popular form of domestic tourism. In Rogerson, C.M. \& Visser, G. (eds), Tourism and development issues in contemporary South Africa, p78IOI. African Institute of SA, Pretoria.

Ryan, C (I99I). UK package holiday industry. Tourism Management, March, 76-77.

SA Tourism. (2004). Global competitiveness study-integrated presentation, August 2004. Pretoria: Department of Environmental Affairs and Tourism (DEAT) and DTI.

SA Tourism. (2007). Tourism growth strategy, 2008-20IO, 3rd ed.: gearing up to be globally competitive. DEAT, Pretoria.

SA Tourism. (2008). The Marketing growth strategy for South Africa, 2008-20IO, May.

SA Tourism. (2OIO). 2009 Annual Tourism Report_vI3_O7O72OIO. SA Tourism.

Sheldon, P.J. \& Mak, J. (1987). The demand for package tours: a mode choice model. Journal of Travel Research, Winter, 25, I3-I7.

Sheldon, P.J. (I994). Tour operators. In Witt, S.F. \& Moutinho, L. (eds), Tourism marketing and management handbook, 2nd ed., p.399-403. Prentice Hall, Cambridge.

Telfer, D.J. \& Sharpley, R. (2008). Tourism and development in the developing world. Routledge, Oxon.

Tustin, D.H., Ligthelm, A.A., Martins, J.H., \& Van Wyk, HdeJ. (2OO5). Marketing research in practice. Unisa Press, Pretoria.

Urry, J. (20O2). The tourist gaze, 2nd ed. Sage Publications, London.

Van Wijk, J. \& Persoon, W. (2006). A long-haul destination; sustainability reporting among tour operators. European Management Journal, 24 (6), 38I-395.

Wang, K-C., Hsieh, A-T. \& Chen, W-Y. (2OO2). Is the tour leader an effective endorser for group package tour brochures? Tourism Management, 23, 489-498.

Wang, K-C., Hsieh, A-T., Chou, S-H. \& Lin, Y-S. (2007). GPTCCC: an instrument for measuring group package tour service. Tourism Management, 28, 36I-376. 
Wang, K-C., Hsieh, A-T. \& Huan, T-C. (2OOO). Critical service features in group package tours: an exploratory research. Tourism Management, 23, 489-498.

Wang, K-C., Hsieh, A-T., Yeh, Y-C. \& Tsai, C-H. (2004). Who is the decision-maker: the parents or the child in group package tours? Tourism Management, 25, I83-I94.

Wong, C-K.S. \& Kwong, W-Y.Y. (2004). Outbound tourists' selection criteria for choosing all-inclusive package tours. Tourism Management, 25, 58I-592. 